Article

\title{
Reversible-Deactivation Radical Polymerization of Methyl Methacrylate Induced by Photochemical Reduction of Various Copper Catalysts
}

\author{
Jaroslav Mosnáček ${ }^{1, *}$, Anna Kundys ${ }^{1,2}$ and Anita Andicsová 1 \\ 1 Polymer Institute, Slovak Academy of Sciences, Dubravska cesta 9, 84541 Bratislava, Slovakia; \\ E-Mails: akundys@ch.pw.edu.pl (A.K.); upolaani@savba.sk (A.A.) \\ 2 Faculty of Chemistry, Warsaw University of Technology, Noakowskiego 3, 00-664 Warsaw, Poland \\ * Author to whom correspondence should be addressed; E-Mail: jaroslav.mosnacek@savba.sk; \\ Tel.: +421-2-3229-4353; Fax: +421-2-3229-4319.
}

External Editor: Nicolay V. Tsarevsky

Received: 15 September 2014; in revised form: 28 October 2014 / Accepted: 4 November 2014 / Published: 14 November 2014

\begin{abstract}
Photochemically mediated reversible-deactivation radical polymerization of methyl methacrylate was successfully performed using 50-400 ppm of various copper compounds such as $\mathrm{CuSO}_{4} \cdot 5 \mathrm{H}_{2} \mathrm{O}$, copper acetate, copper triflate and copper acetylacetonate as catalysts. The copper catalysts were reduced in situ by irradiation at wavelengths of 366-546 nm, without using any additional reducing agent. Bromopropionitrile was used as an initiator. The effects of various solvents and the concentration and structure of ligands were investigated. Well-defined polymers were obtained when at least 100 or 200 ppm of any catalyst complexed with excess tris(2-pyridylmethyl)amine as a ligand was used in dimethyl sulfoxide as a solvent.
\end{abstract}

Keywords: atom transfer radical polymerization; photopolymerization; methyl methacrylate; UV light; visible light; living/controlled polymerization

\section{Introduction}

Atom transfer radical polymerization (ATRP) is one of the most powerful reversible-deactivation radical polymerization (RDRP) techniques. In recent years, many variations of ATRP have been 
developed [1-4]. ATRP with activators generated by electron transfer (AGET) enables the use of the air-stable forms of catalyst complexes, which are reduced in situ to their respective activators by various reducing agents [1,2]. This principle was found to also be applicable for systems with diminished metal catalyst concentrations as low as $10 \mathrm{ppm}$ in activators regenerated by electron transfer (ARGET) or initiators for continuous activator regeneration (ICAR) ATRP [3-5]. These systems are employed in the presence of an excess amount of reducing agent, whereas metal activators are continuously regenerated from metals in higher oxidation state deactivators. RDRP has also been performed in polar solvents such as dimethyl sulfoxide (DMSO) or water, in the presence of elemental metals such as copper or iron. Two mechanisms have been proposed for RDRP in the presence of $\mathrm{Cu}^{0}$ in polar solvents [6]. In the first mechanism, called single electron transfer living radical polymerization (SET-LRP), $\mathrm{Cu}^{0}$ acts as a major activator of alkyl halides and $\mathrm{Cu}^{\mathrm{II}}$ as a major deactivator, whereas $\mathrm{Cu}^{\mathrm{I}}$ rapidly disproportionates to $\mathrm{Cu}^{0}$ and $\mathrm{Cu}{ }^{\mathrm{II}}$. In the second proposed mechanism, called supplemental activator and reducing agent (SARA) ATRP, $\mathrm{Cu}^{0}$ acts as a supplemental activator and reducing agent for $\mathrm{Cu}^{\mathrm{II}}$, whereas $\mathrm{Cu}^{\mathrm{I}}$ and $\mathrm{Cu}^{\mathrm{II}}$ are the major activator and deactivator, respectively. Regardless of which mechanism is correct, RDRP in the presence of elemental metals provides high polymerization rates with high monomer conversions even when carried out at room temperature.

In recent years, continued effort to extend the possibilities of regulating activation and deactivation steps in ATRP has led to the investigation of various external stimuli such as pressure and electrochemical or photochemical parameters. The use of photochemical stimuli in polymerization has particular advantages because photochemical processes are extremely fast, no volatile organic compounds are usually released, and photochemical initiation can be performed at low temperatures with a highly specified course of polymerization, etc. [7,8]. In the past, only a few studies have investigated photochemically initiated ATRP. As a first, Qin et al. reported a photo ATRP-initiating system consisting of 2,2-dimethoxy-2-phenylacetophenone (DMPA)/ferric tri( $N, N$-diethyldithiocarbamate) [Fe(dtc) 3 ] for the polymerization of methyl methacrylate (MMA) [9]. Dithiocarbamates in combination with a copper catalyst were used in the photo ATRP of MMA and $t$-butyl methacrylate (BMA) by Kwak et al. [10] and Ishizu et al. [11]. The Yagci group [12,13] described the in situ photochemical reduction of $\mathrm{CuBr}_{2}$ /PMDETA (pentamethyldiethylenetriamine) to a $\mathrm{CuBr} / \mathrm{PMDETA}$ activator, which subsequently activated an $\mathrm{R}-\mathrm{Br}$ initiator and initiated the polymerization of MMA at ambient temperature. In addition, the polymerization was observed to be accelerated under irradiation [13-15]. In all of these studies, however, the copper catalyst and the initiator were used in equimolar amounts. Recently, our group reported that photochemically mediated ATRP of MMA in anisole can be performed with $50-100 \mathrm{ppm}$ of $\mathrm{CuBr}_{2} / \mathrm{L}$ catalyst while preserving good control over the molar mass and obtaining a narrow dispersity [15]. More recently, the Matyjaszewski group extended this work by investigating the application of several wavelengths in the visible light region for the polymerization of various monomers in dimethyl formamide (DMF) [16]. Very recently, the photopolymerization of various acrylates mediated by copper bromide catalyst was performed in DMSO, and it was shown that an excess amount of the ligand used is needed for polymerization [17-19]. Generally, using a photochemically induced RDRP system (photoRDRP) with a low concentration of catalyst has the advantages of reducing the amount of environmentally harmful chemical reducing agents required and avoiding problems associated with the removal of a large amount of catalyst from the polymer product. 
In this work, we studied the applicability of copper compounds other than copper halides for the photoRDRP of methyl methacrylate in DMSO. In particular, a low-cost and widely available catalyst, copper sulfate pentahydrate $\left(\mathrm{CuSO}_{4} \cdot 5 \mathrm{H}_{2} \mathrm{O}\right)$, was investigated, and good control over molar mass and dispersity was observed. Finally, the work was extended by investigating the applicability of various organic copper compounds, which have the advantage of exhibiting better solubility in organic solvents.

\section{Experimental Section}

\subsection{Materials}

Methyl methacrylate (MMA) was purchased from Sigma-Aldrich (St. Louis, MO, USA) and purified before use by passing through a basic alumina column to remove the inhibitor. 2-Bromopropionitrile (BPN), 2-chloropropionitrile (CPN), $N, N, N^{\prime}, N^{\prime \prime}, N^{\prime \prime}$-pentamethyldiethylenetriamine (PMDETA), tris(2-pyridylmethyl)amine (TPMA), tris[2-(dimethylamino)ethyl]amine (Me6TREN), 1,1,4,7,10,10-hexamethyltriethylenetetraamine (HMTETA), copper sulfate pentahydrate, copper triflate $\left(\mathrm{Cu}(\mathrm{OTf})_{2}\right)$, copper acetylacetonate $\left(\mathrm{Cu}(\mathrm{acac})_{2}\right)$, copper(II) bromide, copper acetate $\left(\mathrm{Cu}(\mathrm{OAc})_{2}\right)$ (all from Sigma-Aldrich), copper(II) chloride (Acros Organics, Geel, Belgium) and dimethyl sulfoxide (DMSO) (Alfa Aesar, Ward Hill, MA, USA) were used as received. All other reagents and solvents were purchased from Sigma-Aldrich and used as received without further purification.

\subsection{Photopolymerization}

The following procedure for the photoRDRP of MMA was used. To a 10-mL Schlenk tube containing copper catalyst, evacuated and filled with argon, ligand and argon-purged solvent were added under an argon atmosphere. When a solid ligand was used, it was introduced into the flask at the beginning together with the catalyst. The mixture in the Schlenk tube was stirred for 15 min to form a copper catalyst/ligand complex. Then, the initiator BPN and MMA purged with argon were added to the Schlenk tube under an argon atmosphere, and the mixture was subsequently degassed by three freeze-pump-thaw cycles and back-filled with argon. Photopolymerization using light with a wavelength of $\lambda>350 \mathrm{~nm}$ (i.e., irradiation at $\lambda=366,405,408,436$ and $546 \mathrm{~nm}$ ) was performed using a medium-pressure mercury lamp in a Spectramat apparatus (Ivoclar AG, Schaan, Liechtenstein, glass filter $\lambda=350-550 \mathrm{~nm}$ ). To prevent heating of the sample during irradiation, the Schlenk tube was placed in a double-layer glass tube. In the outer layer of the tube, water thermostatted to $25{ }^{\circ} \mathrm{C}$ was circulated. With such a cooling system, the temperature of the reaction mixture during the photopolymerization process slightly increased but remained between 30 and $35{ }^{\circ} \mathrm{C}$. The distance of each sample from the arc was approximately $10 \mathrm{~cm}$. The power of the light measured at the sample position was approximately $20 \mathrm{~mW} \cdot \mathrm{cm}^{-2}$.

\subsection{Preparation of a Macroinitiator and Chain Extension}

A poly(methyl methacrylate) macroinitiator (PMMA-Br) was prepared using similar procedures to those described above with an MMA/BPN/CuSO $4 \cdot 5 \mathrm{H}_{2} \mathrm{O} / \mathrm{TPMA}$ ratio of 200/1/0.04/0.16 in 25 vol\% DMSO. A PMMA-Br with a $M_{\mathrm{n}}$ of $14,300 \mathrm{~g} / \mathrm{mol}$ and an $M_{\mathrm{w}} / M_{\mathrm{n}}$ of $1.20(62 \%$ conversion at $3.5 \mathrm{~h}$ polymerization) was obtained after passing through an activated neutral alumina column, followed by 
precipitation in $n$-hexane. Chain extension of the PMMA-Br with MMA was performed using an MMA/PMMA-Br/CuSO $4 \cdot 5 \mathrm{H}_{2} \mathrm{O} / \mathrm{TPMA}$ ratio of $600 / 1 / 0.12 / 0.48$ in $50 \mathrm{vol} \% \mathrm{DMSO}$.

\subsection{Analysis}

The molar mass and dispersity of the polymers were analysed using gel permeation chromatography (GPC); the set-up consisted of a Waters (Milford, MA, USA) 515 pump, two PSS (Polymer Standard Service-USA Inc., Amherst, MA, USA) SDV 5- $\mu \mathrm{m}$ columns, $d=8 \mathrm{~mm}, l=300 \mathrm{~mm}$; porosity: $500 \AA+10^{5} \AA$ ) and a Waters 410 differential refractive index detector with tetrahydrofurane (THF) as an eluent at a flow rate of $1.0 \mathrm{~mL} / \mathrm{min}$. Poly(methyl methacrylate) standards were used for calibration. Monomer conversions were determined by ${ }^{1} \mathrm{H}$ NMR (nuclear magnetic resonance) on a $400 \mathrm{MHz}$ VNMRS Varian NMR spectrometer (Palo Alto, CA, USA) equipped with a $5 \mathrm{~mm}{ }^{1} \mathrm{H}-{ }^{19} \mathrm{~F} /{ }^{15} \mathrm{~N}-{ }^{31} \mathrm{P}$ Pulsed Field Gradients: PFG AutoX DB NB probe at $25{ }^{\circ} \mathrm{C}$ in deuterated chloroform as the solvent. UV-vis absorption spectra were measured on a SPECORD M40 (Carl Zeiss, Jena, Germany) spectrophotometer.

\section{Results and Discussion}

\subsection{Photopolymerization of MMA Using $\mathrm{CuSO}_{4} \cdot 5 \mathrm{H}_{2} \mathrm{O} / \mathrm{TPMA}$ Catalyst Complex in Various Solvents}

Recently, it was published that $\mathrm{CuSO}_{4} \cdot 5 \mathrm{H}_{2} \mathrm{O}$ was able to control the polymerization of methyl methacrylate when a reducing agent, such as ascorbic acid or $\mathrm{Fe}^{0}$, was used [20]. In that study, however, a large amount of the copper catalyst, in an equimolar ratio to an alkyl halide initiator, was used. Therefore, in our study, we decided to investigate the possibility of finding the polymerization conditions for photochemically mediated RDRP using only ppm amounts of $\mathrm{CuSO}_{4} \cdot 5 \mathrm{H}_{2} \mathrm{O}$. UV-vis light with wavelengths over $365 \mathrm{~nm}$ was used to photochemically reduce the catalyst without addition of any other reducing agent.

Initially, three different solvents, anisole, DMF and DMSO, were tested to select the best one for all further studies. Based on our previous experience, BPN and TPMA were used as an initiator and ligand, respectively, for these experiments. The $\mathrm{CuSO}_{4} \cdot 5 \mathrm{H}_{2} \mathrm{O}$ catalyst was used at a concentration of $8.5 \times 10^{-4} \mathrm{~mol} / \mathrm{L}$ (200 ppm with respect to monomer). It should be noted that even though the amount of $\mathrm{CuSO}_{4} \cdot 5 \mathrm{H}_{2} \mathrm{O} / \mathrm{TPMA}$ complex used was completely soluble in pure DMSO, after the addition of MMA it was partially precipitated. On the other hand, in pure anisole, the $\mathrm{CuSO}_{4} \cdot 5 \mathrm{H}_{2} \mathrm{O} / \mathrm{TPMA}$ complex did not completely dissolve. As shown in Figure 1a, the photoRDRP of MMA in anisole was the slowest, whereas in DMSO it was much faster than that in either anisole or DMF. In all cases, the polymerization did not follow first-order kinetics, but an increase in polymerization rate with time was observed. This trend could likely be explained by the progressive dissolution of all insoluble parts of the $\mathrm{CuSO}_{4} \cdot 5 \mathrm{H}_{2} \mathrm{O} / \mathrm{TPMA}$ complex due to the progressive reduction of the soluble part of the $\mathrm{CuSO}_{4} \cdot 5 \mathrm{H}_{2} \mathrm{O} / \mathrm{TPMA}$ complex. When the content of DMSO was increased from $25 \mathrm{vol} \%$ to $75 \mathrm{vol} \%$ to increase the solubility of the complex, the polymerization followed first-order kinetics (see Figure 1a). In Figure 1b, it is shown that although the molar masses agree well with the theoretical ones and a dispersity of approximately 1.2 was obtained in DMSO, in DMF the polymers with slightly higher molar masses and slightly broader dispersities were formed. Contrary to those in anisole, polymers with much higher molar masses and dispersities of approximately 2 were obtained. The reason may be the very low 
solubility of the $\mathrm{CuSO}_{4} \cdot 5 \mathrm{H}_{2} \mathrm{O} / \mathrm{TPMA}$ complex in anisole leading to an insufficient amount of the catalyst in the system and/or the insufficiently fast formation of the $\mathrm{CuBr}$ /TPMA deactivator.

Figure 1. (a) Kinetic plots and (b) evolution of the molar mass and $M_{\mathrm{w}} / M_{\mathrm{n}}$ with the conversion of MMA during photoRDRP using $\mathrm{CuSO}_{4} \cdot 5 \mathrm{H}_{2} \mathrm{O} / \mathrm{TPMA}$ catalyst complex in various solvents. BPN was used as an initiator. Experimental conditions: photoRDRP, MMA/BPN $/ \mathrm{Cu}^{\mathrm{II}} / \mathrm{L}=200 / 1 / 0.04 / 0.16$, irradiation at $\lambda>350 \mathrm{~nm}$; in all experiments: $[\mathrm{MMA}]=7.5 \mathrm{M}, T=35^{\circ} \mathrm{C}, 25 \mathrm{vol} \%$ of solvent.

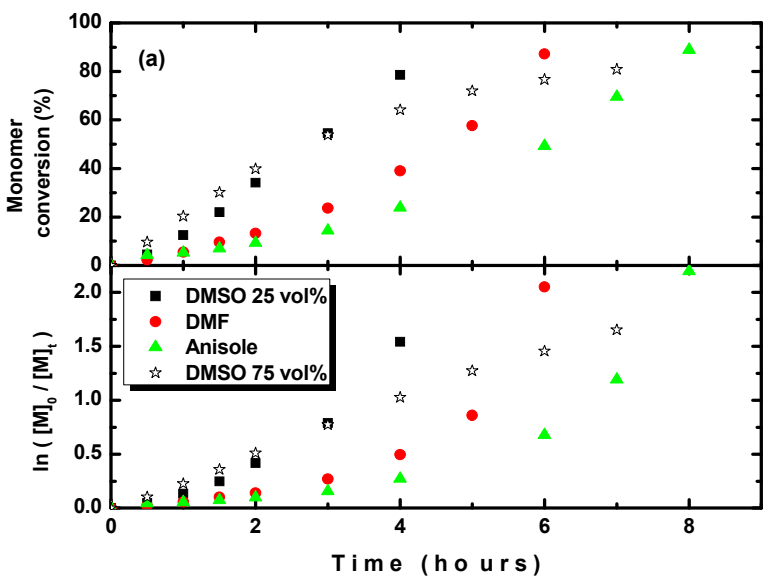

(a)

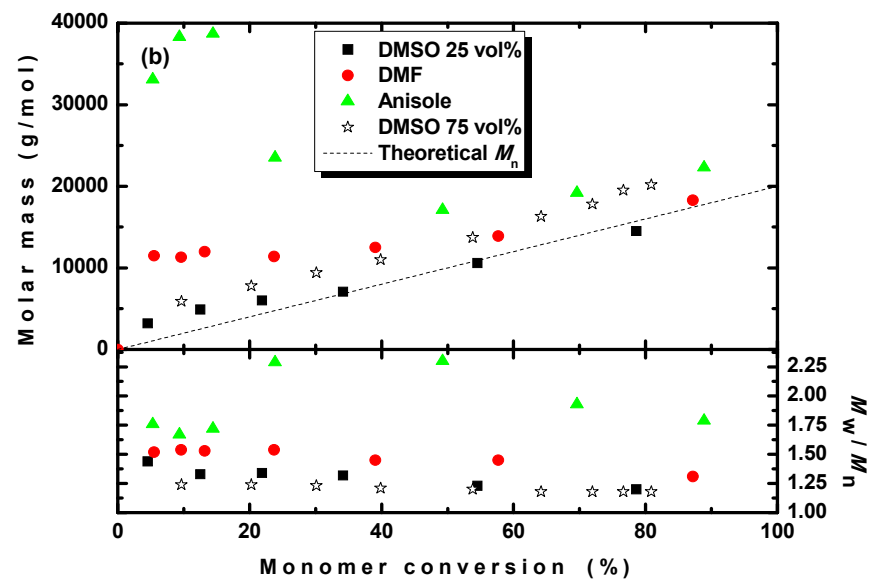

(b)

To confirm the formation of $\mathrm{CuBr}_{2}$ /TPMA deactivator in situ after the photochemical reduction of the $\mathrm{CuSO}_{4} \cdot 5 \mathrm{H}_{2} \mathrm{O} / \mathrm{TPMA}$ complex and subsequent abstraction of bromide from the alkyl bromide initiator, changes in the UV-vis spectra after various periods of irradiation in DMSO were monitored. As shown in Figure 2, the original spectra of the $\mathrm{CuSO}_{4} \cdot 5 \mathrm{H}_{2} \mathrm{O} / \mathrm{TPMA}$ complex varied during irradiation. A progressive increase in absorbance in the region of 700-800 nm was observed, whereas a shoulder in this region, typical for the $\mathrm{CuSO}_{4} \cdot 5 \mathrm{H}_{2} \mathrm{O} / \mathrm{TPMA}$ complex, transformed after 60 min of irradiation into an absorption peak at $\lambda_{\max }=742 \mathrm{~nm}$. A similar spectrum featuring an absorption peak at $\lambda_{\max }=742 \mathrm{~nm}$ is typical for $\mathrm{CuBr}_{2} / \mathrm{TPMA}$ complex.

\subsection{Effect of Ligand Content and Ligand Structure on Photopolymerization of MMA Using $\mathrm{CuSO}_{4} \cdot 5 \mathrm{H}_{2} \mathrm{O}$ Catalyst}

Based on the above-described results, DMSO was chosen as a solvent for all further studies. It was recently reported that excess ligand was essential to the photoRDRP of acrylates when a $\mathrm{CuBr}_{2} / \mathrm{Me}_{6} \mathrm{TREN}$ catalytic complex was used in DMSO [18,19]. Therefore, we tested how the $\mathrm{CuSO}_{4} \cdot 5 \mathrm{H}_{2} \mathrm{O} / \mathrm{TPMA}$ ratio affected the polymerization of MMA. As shown in Figure 3, the polymerization was slightly faster when excess ligand was used. In addition, although with excess ligand the molar masses agreed well with the theoretical ones, in the case of an equimolar ratio of ligand to copper catalyst, molar masses slightly higher than the theoretical ones were obtained. On the other hand, in both cases, the dispersities were narrow. Thus, even though the polymerization could also proceed using an equimolar ratio of the ligand, better control over the molar mass and slightly faster polymerization could be achieved using excess ligand. This finding indicates the possible 
participation of the tertiary amine in the photochemical reduction of the $\mathrm{Cu}^{\mathrm{II}}$ catalyst, as recently suggested for $\mathrm{CuBr}_{2}$ during the photoRDRP of acrylates [19], even though in the latter case no polymerization of acrylates was observed when an equimolar ratio of $\mathrm{CuBr}_{2}$ and $\mathrm{Me}_{6} \mathrm{TREN}$ was used.

Figure 2. UV-vis spectra of $\mathrm{CuSO}_{4} \cdot 5 \mathrm{H}_{2} \mathrm{O} / \mathrm{TPMA}$ complex in DMSO before irradiation and after 30 and $60 \mathrm{~min}$ of irradiation at $\lambda>350 \mathrm{~nm}$ and $\mathrm{UV}$-vis spectrum of $\mathrm{CuBr} 2 / \mathrm{TPMA}$ complex.

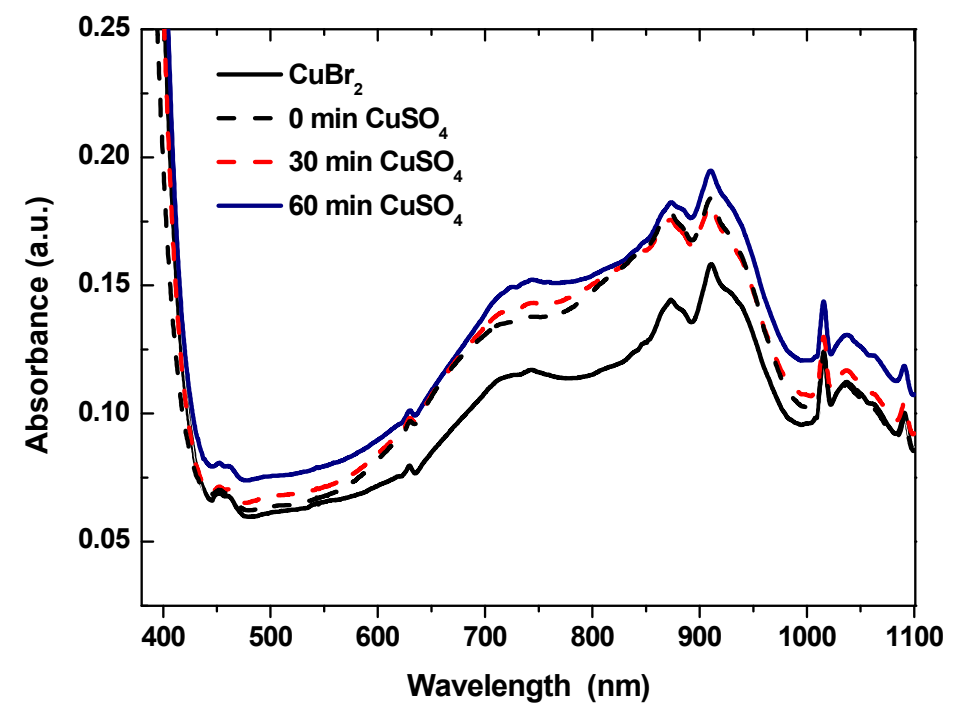

Figure 3. (a) Kinetic plots and (b) evolution of the molar mass and $M_{\mathrm{w}} / M_{\mathrm{n}}$ with the conversion of MMA during photoRDRP using $\mathrm{CuSO}_{4} \cdot 5 \mathrm{H}_{2} \mathrm{O} / \mathrm{TPMA}$ ratios of $1 / 1$ and $1 / 4$. $\mathrm{BPN}$ was used as an initiator. Experimental conditions: photoRDRP, MMA/BPN $/ \mathrm{Cu}^{\mathrm{II}}=$ $200 / 1 / 0.04$, irradiation at $\lambda>350 \mathrm{~nm}$; $[\mathrm{MMA}]=7.5 \mathrm{M}, T=35^{\circ} \mathrm{C}$, DMSO $(25 \mathrm{vol} \%)$.

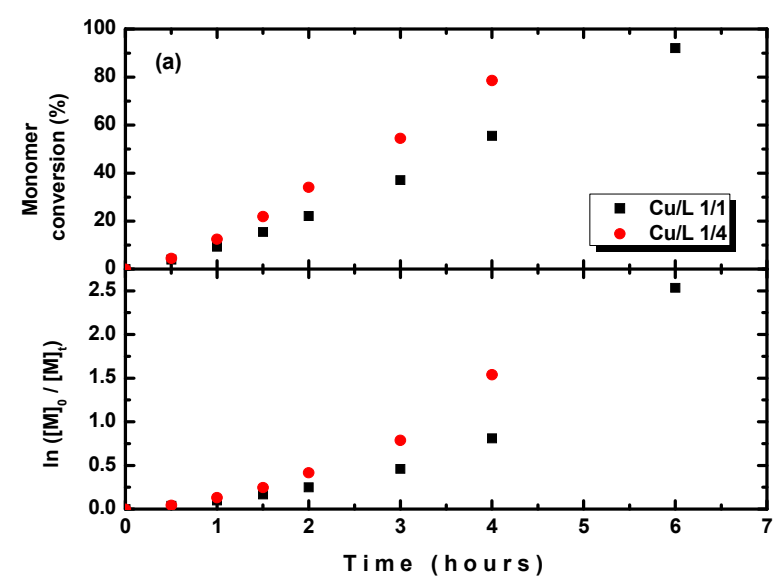

(a)

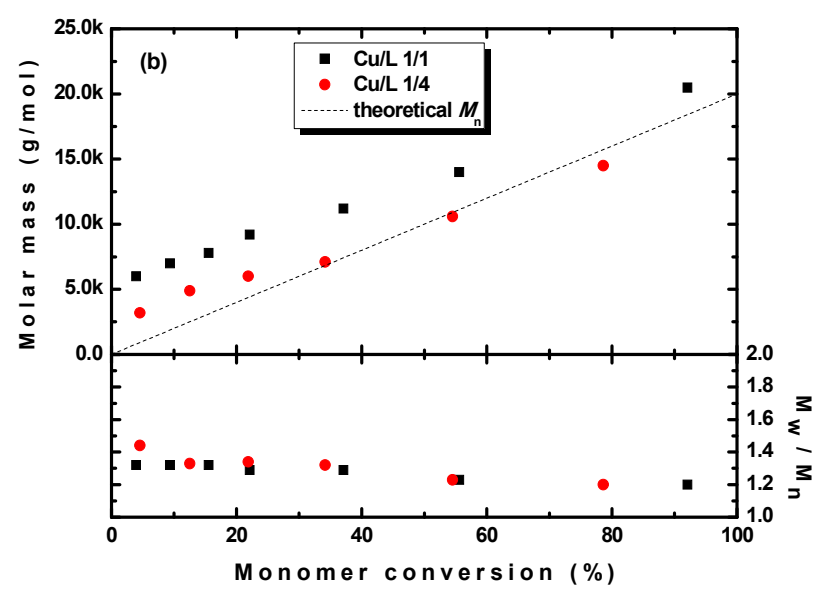

(b)

To investigate the effect of the type of ligand used, three other ligands were evaluated. In all cases, the $\mathrm{CuSO}_{4} \cdot 5 \mathrm{H}_{2} \mathrm{O} /$ ligand (L) ratio was maintained at 1/4. As shown in Table 1, Entries 1-4, after $3 \mathrm{~h}$ of irradiation, a monomer conversion similar to that obtained for TPMA was observed for Me 6 TREN, which is known to form more active complexes in normal ATRP. In contrast, ligands such as PMDETA and HMTETA, which are known to form less active complexes, yielded lower conversions after $3 \mathrm{~h}$ of irradiation. This observation was also confirmed by kinetic studies (see Figure 4a), in which similar rates of polymerization were obtained for the TPMA and Me6TREN ligands and 
slightly lower polymerization rates were obtained for the PMDETA and HMTETA ligands. However, a comparison of the dispersities after $3 \mathrm{~h}$ of polymerization (see Table 1, Entries 1-4) revealed much broader dispersities for all three additionally tested ligands, i.e., Me6TREN, PMDETA and HMTETA, than the dispersity observed for TPMA. Kinetic studies also showed that the molar masses were higher than the theoretical ones for the Me6TREN, PMDETA and HMTETA ligands, and only when TPMA was used did the molar masses agree well with the theoretical ones (see Figure 4b).

Figure 4. (a) Kinetic plots and (b) evolution of the molar mass and $M_{\mathrm{w}} / M_{\mathrm{n}}$ with the conversion of MMA during photoRDRP using $\mathrm{CuSO}_{4} \cdot 5 \mathrm{H}_{2} \mathrm{O}$ catalyst and various ligands (L). BPN was used as an initiator. Experimental conditions: photoRDRP, MMA/BPN $/ \mathrm{Cu}^{\mathrm{II}} / \mathrm{L}=200 / 1 / 0.04 / 0.16$, irradiation at $\lambda>350 \mathrm{~nm}$; in all experiments: $[\mathrm{MMA}]=7.5 \mathrm{M}, T=35^{\circ} \mathrm{C}$, DMSO $(25 \mathrm{vol} \%)$.

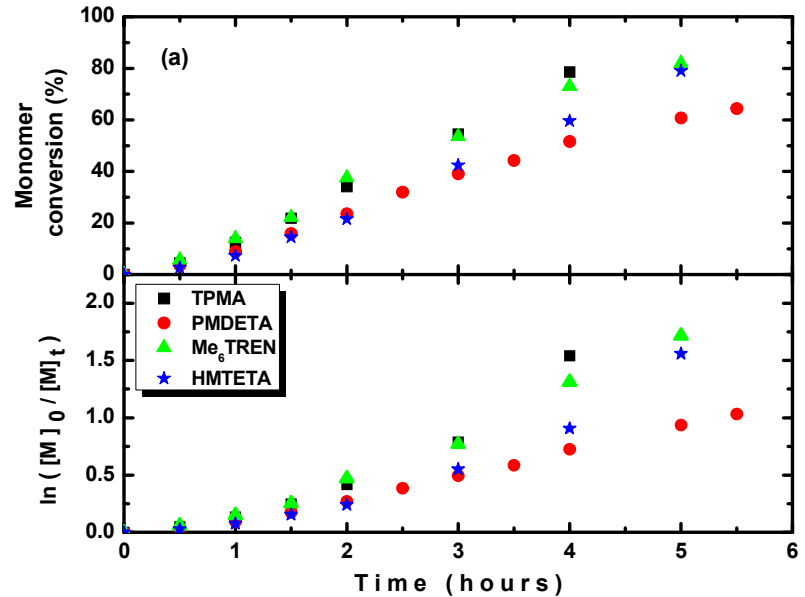

(a)

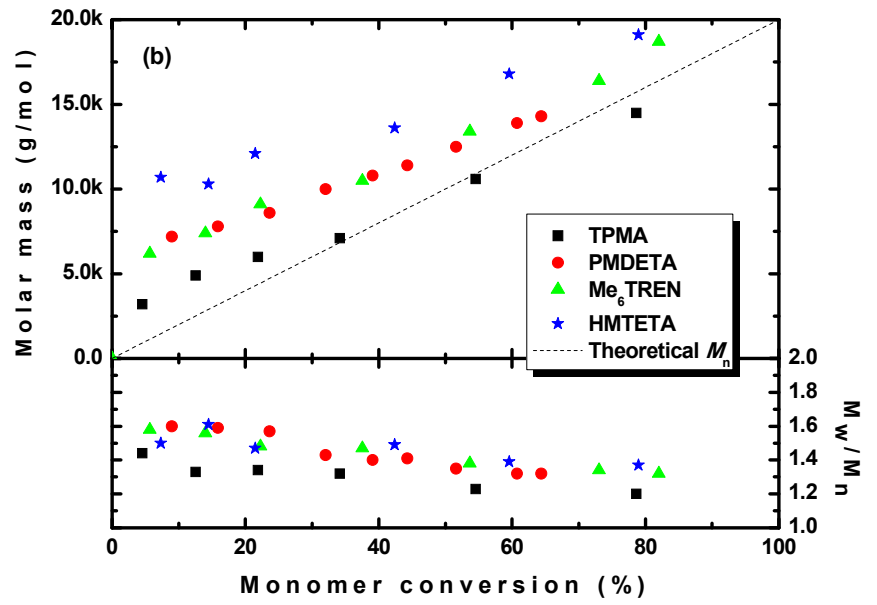

(b)

\subsection{Effect of $\mathrm{CuSO}_{4} \cdot 5 \mathrm{H}_{2} \mathrm{O}$ Catalyst Concentration on Photopolymerization of MMA}

In this section, the effect of the $\mathrm{CuSO}_{4} \cdot 5 \mathrm{H}_{2} \mathrm{O}$ catalyst concentration in the range of 50-400 ppm was investigated while the concentrations of all other species, including the initiator and ligand, were held constant. A summary of the experiments is provided in Table 1, Entries 1 and 5-7. The monomer conversion after $3 \mathrm{~h}$ was nearly the same regardless of whether 100, 200 or $400 \mathrm{ppm}$ of catalyst with respect to the monomer was used. Nearly the same molar masses and dispersities were also obtained. This result suggests that regardless of the concentration of the catalyst, the solubility of the catalyst could be the limiting factor for both the polymerization rate as well as for the molar mass and dispersity evolution. On the other hand, reducing the catalyst concentration to $50 \mathrm{ppm}$ (see Table 1, Entry 7) led to a decrease in monomer conversion after $3 \mathrm{~h}$ of irradiation. At the same time, the molar mass was slightly higher than the theoretical one and the dispersity was slightly broader, despite still being below 1.3. Because in this case the ligand was in sixteen-fold excess, we further tried to reduce the ligand concentration to only four-fold excess to maintain a copper/ligand ratio of $1 / 4$, as in the studies described in previous sections. As shown in Table 1, Entry 8, this decrease in the ligand concentration led to a further decrease in the polymerization rate. At the same time, the difference between the experimental and theoretical molar masses was slightly higher. This finding confirmed the effect of the ligand concentration on the polymerization rate and the control of polymerization with respect to molar mass evolution described in the previous section. 
Table 1. Results of photoRDRP of methyl methacrylate. Polymerizations were performed in $25 \mathrm{vol} \% \mathrm{DMSO}$ at $35{ }^{\circ} \mathrm{C}$ with a monomer/initiator ratio of $200 / 1$. Concentration of $\mathrm{Cu}^{\mathrm{II}}$ catalyst in ppm with respect to that of the monomer; 2-bromopropionitrile and 2-chloropropionitrile were used as initiators in Entries 1-13 and 14-15, respectively. Monomer conversion was determined from ${ }^{1} \mathrm{H}$ NMR spectra and molar mass and dispersity by GPC using PMMA standards.

\begin{tabular}{cccccccccc}
\hline \multirow{2}{*}{ Entry } & $\begin{array}{c}\text { Type of } \\
\mathbf{C u}(\mathbf{I I})\end{array}$ & $\begin{array}{c}\mathbf{C u}(\mathbf{I I}) \\
(\mathbf{p p m})\end{array}$ & Ligand & $\begin{array}{c}\mathbf{C u}(\mathbf{I I}) / \mathbf{L} \\
\text { ratio }\end{array}$ & $\begin{array}{c}\text { Time } \\
{[\mathbf{h}]}\end{array}$ & $\begin{array}{c}\text { Conv. } \\
(\mathbf{\%})\end{array}$ & $\begin{array}{c}\boldsymbol{M}_{\mathbf{n}, \text { theor }} \\
(\mathbf{g} / \mathbf{m o l})\end{array}$ & $\begin{array}{c}\boldsymbol{M}_{\mathbf{n} \text {, exp. }} \\
(\mathbf{g} / \mathbf{m o l})\end{array}$ & $\boldsymbol{M}_{\mathbf{w}} / \boldsymbol{M}_{\mathbf{n}}$ \\
\hline 1 & $\mathrm{CuSO}_{4}$ & 200 & TPMA & $1 / 4$ & 3 & 55 & 11,130 & 10,600 & 1.23 \\
2 & $\mathrm{CuSO}_{4}$ & 200 & PMDETA & $1 / 4$ & 3 & 39 & 7,930 & 10,800 & 1.40 \\
3 & $\mathrm{CuSO}_{4}$ & 200 & HMTETA & $1 / 4$ & 3 & 42 & 8,530 & 13,600 & 1.49 \\
4 & $\mathrm{CuSO}_{4}$ & 200 & $\mathrm{Me}_{6}$ TREN & $1 / 4$ & 3 & 54 & 10,930 & 13,400 & 1.38 \\
5 & $\mathrm{CuSO}_{4}$ & 400 & TPMA & $1 / 2$ & 3 & 53 & 10,730 & 11,200 & 1.22 \\
6 & $\mathrm{CuSO}_{4}$ & 100 & TPMA & $1 / 8$ & 3 & 58 & 11,730 & 11,200 & 1.22 \\
7 & $\mathrm{CuSO}_{4}$ & 50 & TPMA & $1 / 16$ & 3 & 44 & 8,930 & 10,800 & 1.28 \\
8 & $\mathrm{CuSO}_{4}$ & 50 & TPMA & $1 / 4$ & 3 & 37 & 7,530 & 11,200 & 1.30 \\
9 & ${\mathrm{Cu}\left(\mathrm{OTf}_{2}\right.}_{2}$ & 200 & TPMA & $1 / 4$ & 3 & 56 & 11,330 & 12,000 & 1.20 \\
10 & ${\mathrm{Cu}\left(\mathrm{OAc}_{2}\right.}_{11}$ & 200 & TPMA & $1 / 4$ & 3 & 62 & 12,530 & 15,800 & 1.16 \\
11 & ${\mathrm{Cu}\left(\mathrm{acac}_{2}\right.}_{12} 200$ & TPMA & $1 / 4$ & 3 & 56 & 11,330 & 11,800 & 1.31 \\
12 & $\mathrm{CuBr}_{2}$ & 200 & TPMA & $1 / 4$ & 3 & 58 & 11,730 & 11,600 & 1.13 \\
13 & $\mathrm{CuCl}_{2}$ & 200 & TPMA & $1 / 4$ & 3 & 61 & 12,330 & 15,200 & 1.15 \\
14 & $\mathrm{CuCl}_{2}$ & 100 & TPMA & $1 / 1$ & 3 & 5 & 1,130 & 7,800 & 1.47 \\
15 & $\mathrm{CuCl}_{2}$ & 500 & TPMA & $1 / 1$ & 6 & 18 & 3,730 & 9,600 & 1.33 \\
\hline
\end{tabular}

\subsection{Chain Extension PhotoRDRP Using $\mathrm{CuSO}_{4} \cdot 5 \mathrm{H}_{2} \mathrm{O} / \mathrm{TPMA}$ Catalyst Complex}

The living character of the photoRDRP catalyzed by $\mathrm{CuSO}_{4} \cdot 5 \mathrm{H}_{2} \mathrm{O} / \mathrm{TPMA}$ was demonstrated by the chain extension of a PMMA-Br macroinitiator. The PMMA-Br macroinitiator $\left(M_{\mathrm{n}}=14,300 \mathrm{~g} / \mathrm{mol}\right.$ and $\left.M_{\mathrm{w}} / M_{\mathrm{n}}=1.20\right)$ was prepared by photoRDRP under experimental conditions similar to those described above, with an MMA/BPN/CuSO $4 \cdot 5 \mathrm{H}_{2} \mathrm{O} / \mathrm{TPMA}$ ratio of 200/1/0.04/0.16. The polymerization reaction was terminated after $3.5 \mathrm{~h}$ at $62 \%$ monomer conversion. Chain extension was then performed under identical experimental conditions with an MMA/PMMA-Br/ $\mathrm{CuSO}_{4} \cdot 5 \mathrm{H}_{2} \mathrm{O} / \mathrm{TPMA}$ ratio of $600 / 1 / 0.12 / 0.48$. A higher degree of polymerization was targeted in the chain extension polymerization to provide substantial separation between the macroinitiator and the extended polymer in the GPC traces. After $3 \mathrm{~h}\left(73 \%\right.$ conversion), the chain-extended PMMA with $M_{\mathrm{n}}=49,500 \mathrm{~g} / \mathrm{mol}$ and $M_{\mathrm{w}} / M_{\mathrm{n}}=1.36$ was obtained. As indicated by the GPC traces of the PMMA before and after the chain extension polymerization (Figure 5), the molar mass clearly increased after chain extension. A small tail could be observed, which suggests that some non-extended PMMA chains were present in the polymerization mixture. Considering that at the beginning of the polymerization no deactivator was present in the system until it was formed by the reaction of reduced copper with the initiator, some termination reactions can be expected. The range of the termination reactions should be, however, limited by the rather small amount of catalyst used. 
Figure 5. GPC traces from chain extension of PMMA-Br with MMA; (dash black curve) PMMA-Br macroinitiator and (solid blue curve) chain-extended PMMA after 73\% conversion of MMA. The preparation of the PMMA-Br macroinitiator and the chain extension were performed by photoRDRP using a $\mathrm{CuSO}_{4} \cdot 5 \mathrm{H}_{2} \mathrm{O} / \mathrm{TPMA}$ catalyst complex. Experimental conditions: preparation of PMMA-Br, MMA/BPN/Cu$/ \mathrm{TPMA}=200 / 1 / 0.04 / 0.16$, DMSO (25 vol\%); chain extension: MMA/PMMA-Br/Cu ${ }^{\mathrm{II}} / \mathrm{TPMA}=600 / 1 / 0.12 / 0.48$, DMSO (50 vol\%); in both polymerizations: $[\mathrm{MMA}]=7.5 \mathrm{M}, T=35^{\circ} \mathrm{C}$, irradiation at $\lambda>350 \mathrm{~nm}$.

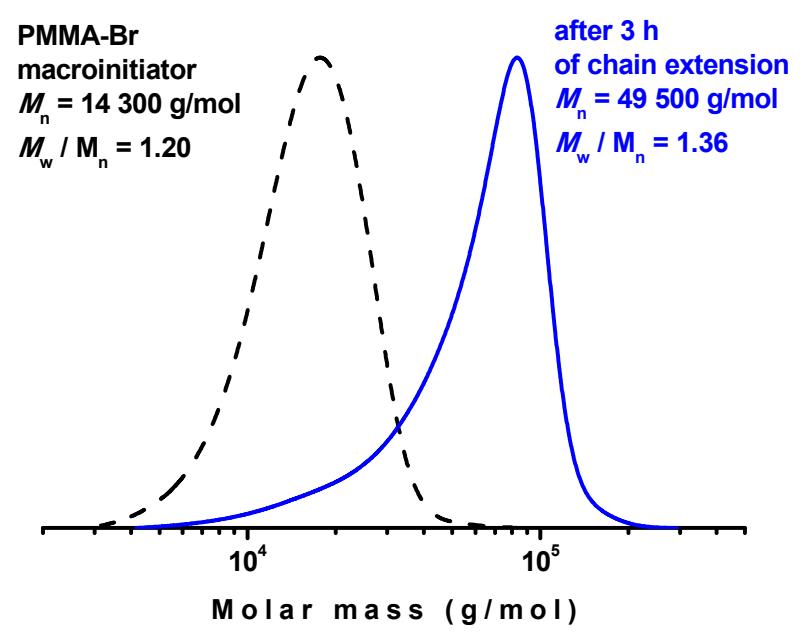

\subsection{Effect of Copper Catalyst Structure on Photopolymerization of MMA}

Because it was observed that the $\mathrm{CuSO}_{4} \cdot 5 \mathrm{H}_{2} \mathrm{O}$ catalyst was able to control the polymerization of methyl methacrylate under photoRDRP conditions, the applicability of other copper compounds in photoRDRP was further investigated. Three different organic copper compounds, copper acetate $\left(\mathrm{Cu}(\mathrm{OAc})_{2}\right)$, copper triflate $\left(\mathrm{Cu}(\mathrm{OTf})_{2}\right)$ and copper acetylacetonate $\left(\mathrm{Cu}(\mathrm{acac})_{2}\right)$, were investigated and compared with commonly used ATRP catalysts, such as $\mathrm{CuBr}_{2}$ and $\mathrm{CuCl}_{2}$. The advantage of the organic copper compounds is their better solubility in organic solvents and thus their ability to support polymerization in homogeneous systems. A concentration of $200 \mathrm{ppm}$ of the catalyst and TPMA in four-fold excess with respect to the catalyst concentration was used in all experiments. A summary of the experiments is provided in Table 1, Entries 9-13. The results show that for all tested copper catalysts, the monomer conversions after $3 \mathrm{~h}$ of irradiation were very similar, falling within the range of $55 \%-62 \%$. Kinetic studies confirmed that the polymerization rate was almost the same for all tested copper catalysts (see Figure 6a). In one of the previous sections, it was demonstrated that the $\mathrm{CuSO}_{4} \cdot 5 \mathrm{H}_{2} \mathrm{O}$ catalyst was transformed in situ into $\mathrm{CuBr}_{2}$. The same polymerization rate for various copper catalysts confirmed this observation. As suggested by the schematic mechanism shown in Scheme 1, regardless of type of catalyst used, the $\mathrm{Cu}^{\mathrm{II}} \mathrm{X}_{2} / \mathrm{L}$ complex, where $\mathrm{X}$ can be $1 / 2\left(\mathrm{SO}_{4}\right)$, OTf, $\mathrm{OAc}$, acac, $\mathrm{Cl}$ or $\mathrm{Br}$, must be photochemically reduced to form the $\mathrm{Cu}^{\mathrm{I}} \mathrm{X} / \mathrm{L}$ complex, which is able to react with alkyl bromide to form an alkyl radical and $\mathrm{Cu}^{\mathrm{II}} \mathrm{XBr} / \mathrm{L}$. The $\mathrm{Cu}^{\mathrm{II}} \mathrm{XBr} / \mathrm{L}$ can subsequently act as a deactivator to form alkyl bromide and $\mathrm{Cu}^{\mathrm{I}} \mathrm{X} / \mathrm{L}$ or can be photochemically reduced to a $\mathrm{Cu} \mathrm{I}^{\mathrm{I}} \mathrm{Br} / \mathrm{L}$ complex and subsequently abstract another bromide from alkyl bromide to form an alkyl radical and $\mathrm{Cu}^{\mathrm{II}} \mathrm{Br}_{2} / \mathrm{L}$. Ultimately, an equilibrium between the $\mathrm{Cu}^{\mathrm{I}} \mathrm{Br} / \mathrm{L}$ and $\mathrm{Cu}^{\mathrm{II}} \mathrm{Br}_{2} / \mathrm{L}$ complexes is reached. Because the $\mathrm{CuBr}_{2}$ catalyst can be expected to form after the reduction of all of the copper catalysts 
studied, regardless of their structure, the polymerization will still be controlled by the $\mathrm{CuBr} / \mathrm{CuBr} 2 / \mathrm{L}$ catalytic system formed in situ.

Figure 6. (a) Kinetic plots and (b) evolution of the molar mass and $M_{\mathrm{w}} / M_{\mathrm{n}}$ with the conversion of MMA during photoRDRP using various copper catalysts. BPN and TPMA were used as the initiator and ligand, respectively. Experimental conditions: photoRDRP, MMA/BPN/Cu ${ }^{\mathrm{II}} / \mathrm{TPMA}=200 / 1 / 0.04 / 0.16$, irradiation at $\lambda>350 \mathrm{~nm}$; in all experiments: $[\mathrm{MMA}]=7.5 \mathrm{M}, T=35^{\circ} \mathrm{C}, \mathrm{DMSO}(25 \mathrm{vol} \%)$.

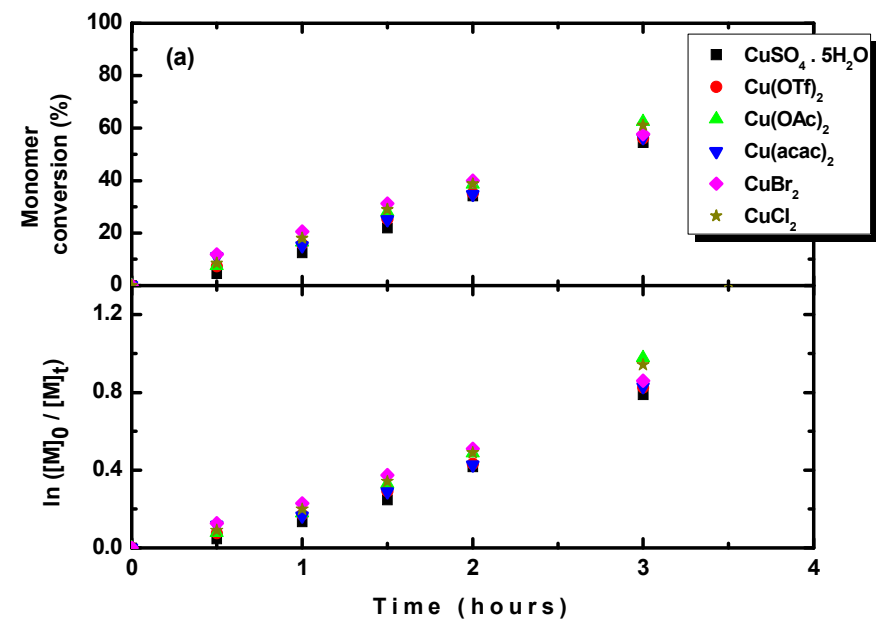

(a)

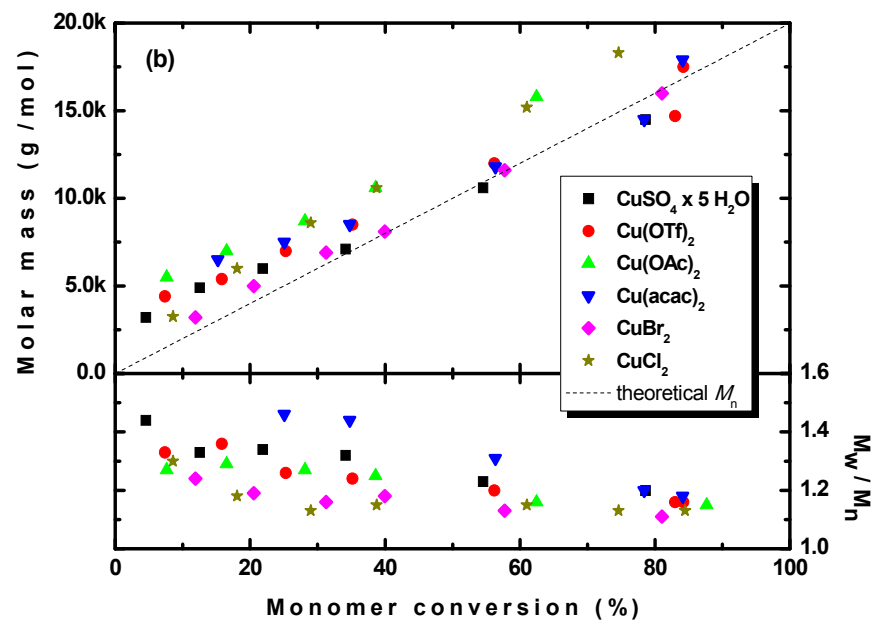

(b)

Scheme 1. Schematic mechanism of photochemical reduction of various copper(II) compounds and subsequent formation of $\mathrm{CuBr} / \mathrm{CuBr} 2$ equilibrium ensuring good control in RDRP.

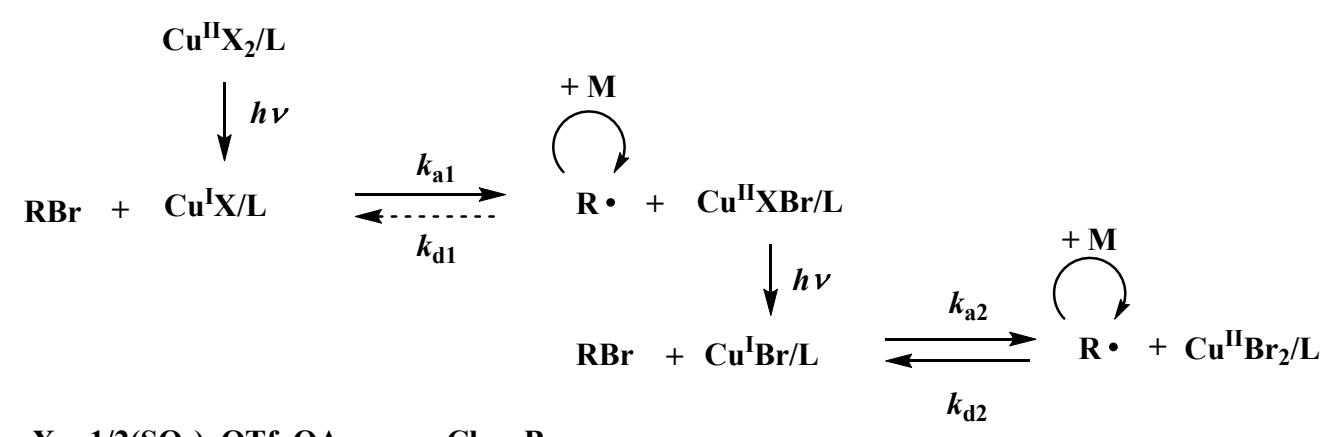

$\mathrm{X}=\mathbf{1 / 2}\left(\mathrm{SO}_{4}\right)$, OTf, OAc, acac, $\mathrm{Cl}$ or $\mathrm{Br}$

$\mathbf{R}=$ alkyl or polymer chain

Slight differences in the evolution of the molar mass and dispersity were observed, where slightly higher molar masses and slightly broader dispersities were observed, mostly at lower conversions, for the $\mathrm{CuSO}_{4} \cdot 5 \mathrm{H}_{2} \mathrm{O}$ and organic copper catalysts compared with those obtained for copper halides. The reason for this observation has already been discussed, i.e., the absence of the deactivator at the beginning of the polymerization. However, except for the cases in which $\mathrm{CuCl}_{2}$ or $\mathrm{Cu}(\mathrm{OAc})_{2}$ were used, for the other catalysts, the molar masses agreed well with the theoretical ones, and dispersities below 1.2 were obtained at higher monomer conversions. 
It should also be noted that when $100 \mathrm{ppm}$ of $\mathrm{CuCl}_{2}$ /TPMA catalyst complex was used in combination with a chlorinated initiator, such as chloropropionitrile, only $5 \%$ monomer conversion was obtained after $3 \mathrm{~h}$ of irradiation and the obtained molar mass was much higher than the theoretical one (see Table 1, Entry 14). Even after increasing the catalyst concentration to $500 \mathrm{ppm}$, only $18 \%$ monomer conversion was obtained after $6 \mathrm{~h}$ of irradiation, whereas a much higher molar mass than the theoretical one was obtained (see Table 1, Entry 15). These results suggest that initiation (activation) of chloride-based initiators is not sufficiently fast to be applicable in the photoRDRP of methyl methacrylate.

Based on the submitted mechanism, the $\mathrm{CuBr} / \mathrm{CuBr}_{2}$ equilibrium could be obtained by photochemical reduction of any copper catalyst prior to the addition of monomer and thus improved control over molar mass and dispersity could be achieved. Therefore, the $\mathrm{CuSO}_{4} \cdot 5 \mathrm{H}_{2} \mathrm{O} / \mathrm{TPMA}$ complex was first pre-irradiated in DMSO in the presence of BPN as an alkyl bromide initiator for $1 \mathrm{~h}$ to obtain the $\mathrm{CuBr} / \mathrm{CuBr}_{2}$ equilibrium. Subsequently a MMA was added to initiate the polymerization. As shown in Figure 7, the kinetic of polymerization was similar whether monomer was added before irradiation or after $1 \mathrm{~h}$ of irradiation. In the first case, slight curvature was observed due to progressive dissolving of the catalyst, as already described above, whereas in the case of pre-irradiation, the dependence from the beginning followed the first order kinetic due to achieving a more homogeneous system during pre-irradiation. A larger difference, however, was observed in development of dispersity. In the case of pre-irradiation, the polymer with narrower dispersity was obtained because the pre-irradiation led to formation of $\mathrm{CuBr}_{2}$ deactivator ensuring better control over the molar mass and dispersity.

Figure 7. (a) Kinetic plots and (b) evolution of the molar mass and $M_{\mathrm{w}} / M_{\mathrm{n}}$ with the conversion of MMA during photoRDRP using $\mathrm{CuSO}_{4} \cdot 5 \mathrm{H}_{2} \mathrm{O} / \mathrm{TPMA}$ complex. MMA was added either before irradiation or after $1 \mathrm{~h}$ of pre-irradiation of the solvent containing catalyst, ligand and initiator. Experimental conditions: photoRDRP, $\mathrm{MMA} / \mathrm{BPN} / \mathrm{Cu}^{\mathrm{II}} / \mathrm{TPMA}=200 / 1 / 0.04 / 0.16$, irradiation at $\lambda>350 \mathrm{~nm}$; in all experiments: $[\mathrm{MMA}]=7.5 \mathrm{M}, T=35^{\circ} \mathrm{C}$, DMSO $(25 \mathrm{vol} \%)$.

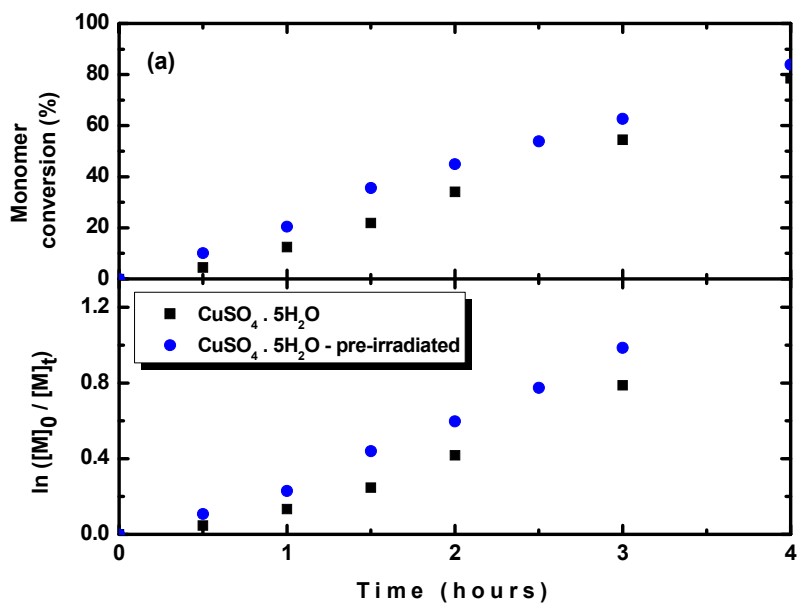

(a)

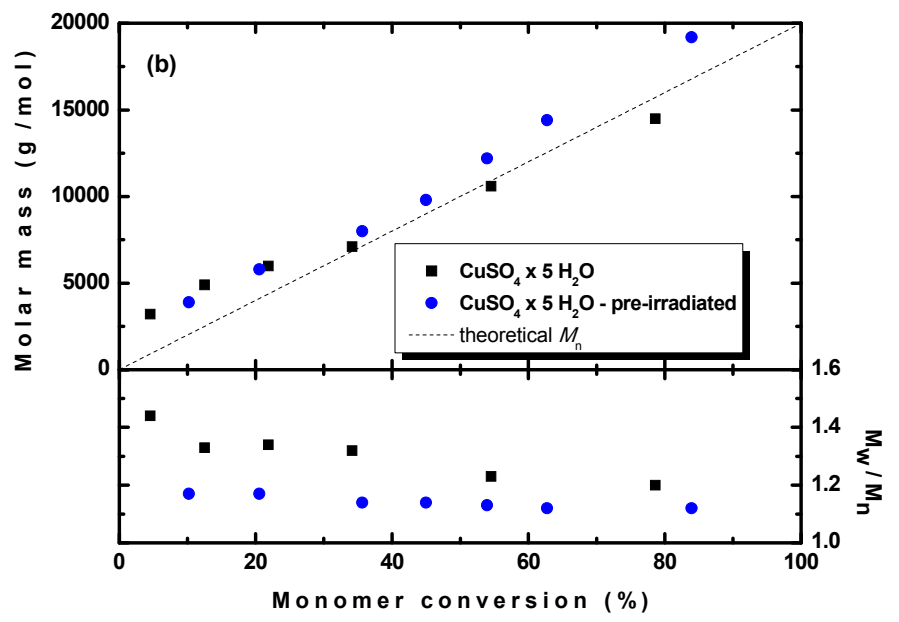

(b) 


\section{Conclusions}

Poly(methyl methacrylate) with a well-defined molar mass and narrow dispersity was successfully prepared by photoRDRP using low-cost and widely available $\mathrm{CuSO}_{4} \cdot 5 \mathrm{H}_{2} \mathrm{O}$ as a catalyst. DMSO and TPMA were found to be the most proper solvent and ligand, respectively, among all of the species investigated. A catalyst concentration of $100 \mathrm{ppm}$ with respect to the monomer concentration was found to be sufficient to exert good control over the molar mass and dispersity. Further increasing the catalyst concentration did not lead either to an increase in the polymerization rate or improved control over polymerization due to the limited solubility of the catalytic complex in the DMSO/MMA mixture. On the other hand, the polymerization was faster and better controlled when excess ligand was used. In addition to $\mathrm{CuSO}_{4} \cdot 5 \mathrm{H}_{2} \mathrm{O}$, three other organic copper compounds, namely copper acetate, copper triflate and copper acetylacetonate, were investigated and compared to copper bromide and copper chloride catalysts. The polymerization rate, as well as control over the molar mass and dispersity of poly(methyl methacrylate), was nearly the same for all of the tested catalysts because in each case the polymerization was controlled by $\mathrm{CuBr} / \mathrm{CuBr} / \mathrm{L}$ catalytic system formed in situ after the photochemical reduction of the investigated copper catalysts.

\section{Acknowledgments}

The authors thank the Slovak Research and Development Agency for the financial support provided through grant APVV-0109-10, Grant Agency VEGA 2/0112/13 as well as the Centre of Excellence of the Slovak Academy of Sciences for Functionalized Multiphase Materials (FUN-MAT). Anna Kundys thanks the European Union for the financial support provide within the framework of the European Social Fund through the Warsaw University of Technology Development Programme, realized by the Center for Advanced Studies.

\section{Author Contributions}

Jaroslav Mosnáček planned the experiments and wrote the manuscript. Anna Kundys and Anita Andicsová performed the experiments.

\section{Conflicts of Interest}

The authors declare no conflict of interest.

\section{References}

1. Min, K.; Gao, H.F.; Matyjaszewski, K. Preparation of homopolymers and block copolymers in miniemulsion by ATRP using activators generated by electron transfer (AGET). J. Am. Chem. Soc. 2005, 127, 3825-3830.

2. Min, K.; Jakubowski, W.; Matyjaszewski, K. AGET ATRP in the presence of air in miniemulsion and in bulk. Macromol. Rapid Commun. 2006, 27, 594-598.

3. Jakubowski, W.; Min, K.; Matyjaszewski, K. Activators regenerated by electron transfer for atom transfer radical polymerization of styrene. Macromolecules 2006, 39, 39-45. 
4. Jakubowski, W.; Matyjaszewski, K. Activators regenerated by electron transfer for atom-transfer radical polymerization of (meth)acrylates and related block copolymers. Angew. Chem. Int. Ed. 2006, 45, 4482-4486.

5. Matyjaszewski, K.; Jakubowski, W.; Min, K.; Tang, W.; Huang, J.Y.; Braunecker, W.A.; Tsarevsky, N.V. Diminishing catalyst concentration in atom transfer radical polymerization with reducing agents. Proc. Natl. Acad. Sci. USA 2006, 103, 15309-15314.

6. Zhong, M.; Wang, Y.; Krys, P.; Konkolewicz, D.; Matyjaszewski, K. Reversible-deactivation radical polymerization in the presence of metallic copper. Kinetic simulation. Macromolecules 2013, 46, 3816-3827.

7. Yagci, Y.; Jockusch, S.; Turro, N.J. Photoinitiated polymerization: Advances, challenges, and opportunities. Macromolecules 2010, 43, 6245-6260.

8. Decker, C. Photoinitiated crosslinking polymerisation. Prog. Polym. Sci. 1996, 21, 593-650.

9. Qin, S.H.; Qin, D.Q.; Qiu, K.Y. A novel photo atom transfer radical polymerization of methyl methacrylate. New J. Chem. 2001, 25, 893-895.

10. Kwak, Y.; Matyjaszewski, K. Photoirradiated atom transfer radical polymerization with an alkyl dithiocarbamate at ambient temperature. Macromolecules 2010, 43, 5180-5183.

11. Ishizu, K.; Katsuhara, H. Diethyldithiocarbamate-mediated living radical polymerization and development for architecture of nanostructured polymers. Des. Monomers Polym. 2006, 9, 99-115.

12. Tasdelen, M.A.; Uygun, M.; Yagci, Y. Photoinduced controlled radical polymerization. Macromol. Rapid Commun. 2011, 32, 58-62.

13. Tasdelen, M.A.; Uygun, M.; Yagci, Y. Photoinduced controlled radical polymerization in methanol. Macromol. Chem. Phys. 2010, 211, 2271-2275.

14. Guan, Z.B.; Smart, B. A remarkable visible light effect on atom-transfer radical polymerization. Macromolecules 2000, 33, 6904-6906.

15. Mosnáček, J.; Ilčíková, M. Photochemically mediated atom transfer radical polymerization of methyl methacrylate using ppm amounts of catalyst. Macromolecules 2012, 45, 5859-5865.

16. Konkolewicz, D.; Schroder, K.; Buback, J.; Bernhard, S.; Matyjaszewski, K. Visible light and sunlight photoinduced ATRP with ppm of Cu catalyst. ACS Macro Lett. 2012, 1, 1219-1223.

17. Anastasaki, A.; Nikolaou, V.; Zhang, Q.; Burns, J.; Samanta, S.R.; Waldron, C.; Haddleton, A.J.; McHale, R.; Fox, D.; Percec, V.; et al. Copper(II)/tertiary amine synergy in photoinduced living radical polymerization: Accelerated synthesis of $\omega$-functional and $\alpha, \omega$-heterofunctional poly(acrylates). J. Am. Chem. Soc. 2014, 136, 1141-1149.

18. Ribelli, T.G.; Konkolewicz, D.; Bernhard, S.; Matyjaszewski, K. How are radicals (re)generated in photochemical ATRP? J. Am. Chem. Soc. 2014, doi:10.1021/ja506379s.

19. Wenn, B.; Conradi, M.; Carreiras, A.D.; Haddleton, D.M.; Junkers, T. Photo-induced copper-mediated polymerization of methyl acrylate in continuous flow reactors. Polym. Chem. 2014, 5, 3053-3060.

20. Zhao, J.; Wang, W.; Bai, L.; Zhou, L.; Cheng, Z.; Zhang, Z.; Zhu, X. Reversible-deactivation radical polymerization mediated by $\mathrm{CuSO}_{4} \cdot 5 \mathrm{H}_{2} \mathrm{O}$ : An alternative and promising copper(II)-based catalyst. Polym. Chem. 2012, 3, 3220-3223.

(C) 2014 by the authors; licensee MDPI, Basel, Switzerland. This article is an open access article distributed under the terms and conditions of the Creative Commons Attribution license (http://creativecommons.org/licenses/by/4.0/). 